\title{
Práticas Ágeis Aplicadas a um Processo de Manutenção de Software: Um Relato de Experiência
}

\author{
André L. B. M. $\operatorname{Ramos}^{1}$, Thiago L. Luna de Lima ${ }^{1}$, Lívia Maria R. V. Cunha ${ }^{1}$, \\ Rafael L. A. Tavares ${ }^{1}$ \\ ${ }^{1}$ Empresa de Tecnologia e Informações da Previdência Social (Dataprev) \\ Caixa Postal 58.013-240 - João Pessoa - PB - Brasil \\ andre.ramos@dataprev.gov.br, thiago.lunalima@dataprev.gov.br, \\ livia.vasconcelos@dataprev.gov.br, rafael.tavares@dataprev.gov.br
}

\begin{abstract}
Many companies do not use a formal process during the software's evolution. This is due to the inadequacy of the traditional characteristics intrinsic to the process of software maintenance, e.g., fast delivery, simplicity in the communication process and closer monitoring of problems. In this context, this paper aims to present the software process, scrum-based agile model, adopted in the Maintenance Area of Dataprev / PB. At the end, we present the survey of subjective satisfaction of the maintenance team regarding adoption of that process.
\end{abstract}

Resumo. Muitas empresas não utilizam um processo formal durante a fase de evolução de software. Este fato decorre da não adequação dos processos tradicionais às características intrínsecas ao processo de manutenção do software, e.g., rápidas entregas, simplicidade no processo de comunicação e acompanhamento mais perto dos problemas. Neste contexto, o presente documento tem como objetivo apresentar o processo de software, baseado no modelo ágil scrum, adotado na Divisão de Manutenção da Dataprev/PB. Ao final, é apresentada a sondagem de satisfação subjetiva da equipe de manutenção em relação à adoção do referido processo.

\section{Introdução}

Nos dias atuais, com ao acirramento da concorrência entre empresas de Tecnologia da Informação, a qualidade do produto desenvolvido torna-se um aspecto essencial na busca pelo aumento de vantagem competitiva. Une-se a este fato o aumento da complexidade dos produtos e da exigência dos clientes e tem-se um cenário que aponta para a necessidade, cada vez mais, da busca pela satisfação dos usuários. Desta forma, do ponto de vista de desenvolvimento de software, a preocupação com a qualidade deve existir em todas as etapas do ciclo de vida do produto, inclusive após a entrega do sistema.

Nesse âmbito, tem-se observado nos últimos tempos a intensificação dos estudos relacionados à atividade de manutenção de software. Este fato é decorrente, dentre outros fatores, da necessidade de garantir a qualidade dos sistemas em funcionamento nas organizações ao redor do mundo. Diversos aspectos podem influenciar na qualidade do método utilizado para manter sistemas existentes, e.g. políticas da empresa, perfil dos clientes, técnicas deficientes utilizadas na construção do produto original (Paduelli, 2007). 
Partindo desse pressuposto, o presente relatório de experiência tem como objetivo a apresentação de um processo e lições aprendidas decorrentes da utilização de boas práticas de modelos ágeis em uma área de manutenção que atua na correção pontual de defeitos e pequenas melhorias.

Uma das principais particularidades a serem discutidas é o fato de existir forte integração entre a área de manutenção e os projetos de desenvolvimento no tocante à evolução dos produtos. Estratégias de gerência de configuração e testes precisaram ser bem definidas, para evitar re-trabalho, correções e melhorias redundantes, além de garantir a qualidade do produto mantido.

\section{Manutenção e Qualidade de Software}

O termo "Qualidade de Software" está inserido no contexto da garantia do correto atendimento às necessidades e anseios dos clientes, tanto no desenvolvimento como também na manutenção de um produto.

A norma ISO 9126-1 (2001) considera manutenibilidade como critério de qualidade de um produto de software ao defini-la como a capacidade/facilidade do produto de software de ser modificado, incluindo tanto as melhorias ou extensões de funcionalidade quanto correções de defeitos, falhas ou erros. Desta forma, pode-se afirmar que manutenibilidade é um dos fatores da qualidade de software, pois se refere à facilidade com que um software pode ser adaptado, aprimorado e/ou corrigido para satisfazer os requisitos especificados, conforme a vontade do cliente.

A atividade de manutenção de software é iniciada após a entrega do produto para o cliente. O objetivo principal desta fase é atender mudanças corretivas, adaptativas e evolutivas provenientes da operação do software pelo usuário (Pressman, 2001; Sommerville, 2007). Neste contexto, é esperado que cada etapa da construção do produto resulte em entregáveis que sejam fáceis de serem lidos, compreendidos e modificados. A manutenção somente pode acontecer eficientemente se as fases anteriores tiverem sido feitas apropriadamente (Erdil 'et al.', 2003). Dentre os problemas detectados na etapa de manutenção de produtos, destaca-se a ausência ou limitação de documentação.

Apesar de a fase de manutenção depender bastante da forma como o produto foi desenvolvido nas etapas anteriores, isto não significa que as atividades dessa etapa devam ter menos prioridade quando o assunto é qualidade do produto. Para justificar esta afirmação, podemos citar a quantidade de situações de produtos que regridem devido à inserção de defeitos originados de impactos de correções e manutenções evolutivas.

\section{O Processo de Manutenção na Dataprev/PB}

Após o desenvolvimento e implantação dos sistemas construídos pela Unidade de Desenvolvimento de Software Paraíba (UDPB), faz-se necessário o acompanhamento e controle das mudanças realizadas para garantir que os produtos permaneçam livres de erros e em concordância com os acordos de nível de serviço previstos em contrato com os clientes.

Nesse contexto, a Divisão de Manutenção de Produtos (DMP1) foi criada em Outubro de 2009 com as atribuições de controlar a implementação de demandas 
evolutivas e adaptativas prioritárias e de curto prazo; Acompanhar as manutenções evolutivas, corretivas, emergenciais, dos produtos implantados; Analisar especificação, verificando a completude, complexidade e natureza da demanda, avaliando o tamanho necessário (em pontos por função) bem como, indicando o prazo para sua execução; Acompanhar o controle de versões do sistema corrigido, de forma que qualquer atualização no sistema seja integrável à versão utilizada nos projetos em desenvolvimento; Controlar a execução, sob demanda, da manutenção corretiva dos componentes de software especificado no requerimento do cliente de acordo com os padrões de arquitetura da Empresa; Garantir a atualização da documentação do sistema conforme demanda de manutenção solicitada; Entregar os componentes de software em conformidade com o requerimento do cliente e atendendo aos níveis de serviço e qualidade especificados; E, por fim, indicar, caso necessário, a incompatibilidade de padrões de codificação através da inspeção de códigos fontes constituídos por terceiros (área de negócios ou cliente).

Pelas características distintas na forma de atendimento das demandas, não seria viável aplicar à manutenção de software o mesmo processo de desenvolvimento adotado durante a construção do produto. Diante disto, como forma de trabalho, buscou-se pela ideia de atender rapidamente as demandas de melhoria e correção de defeitos, onde mudanças necessárias eram realizadas no código-fonte após uma especificação informal, para só depois atualizar a documentação.

Com o aumento do número, da complexidade e urgência das demandas, esta forma de trabalho passou a apresentar problemas: Com o tempo, a documentação dos produtos passou a não ser devidamente atualizada, os testes não foram aplicados como deveriam e os produtos ficaram cada vez mais difíceis de serem mantidos. Como conseqüência, muitos problemas tornaram-se recorrentes e a relação entre demandas criadas e atendidas passou a não suprir as necessidades dos clientes.

Diante desse cenário, percebeu-se a necessidade de adotar um processo que garantisse rápidas entregas para o cliente a fim de aumentar o número de demandas atendidas. Além disto, constatou-se a necessidade de prover uma melhor forma de estabelecer e acompanhar o escopo.

\subsection{O Processo de manutenção Ágil}

Para dar agilidade à forma de manter os produtos na Dataprev/PB, foi proposto um processo que incorpora boas práticas descritas em metodologias ágeis.

De acordo com o processo adotado, inicialmente tem-se uma lista de demandas solicitadas pela área de produtos, responsável pela comunicação com o cliente. Após a reunião de planejamento, com a participação da área de produtos e do líder, são priorizados e definidos os casos a serem tratados na iteração. A priori, não se deve alterar o escopo da iteração. Caso surja uma demanda urgente, esta deve ser priorizada, corrigida e implantada em produção imediatamente. Cada iteração tem duração de quatro semanas, como descrito na Figura 1.

Nas duas primeiras semanas, as demandas são especificadas, com o apoio dos Analistas de Negócio. Além disto, os roteiros dos testes funcionais manuais são elaborados e a contagem de pontos de função é realizada. Neste período, também é realizada a execução dos testes funcionais da iteração anterior. Nas duas semanas 
posteriores, é realizada a codificação e os testes unitários. Por fim, a aplicação atualizada é disponibilizada para homologação com o cliente.

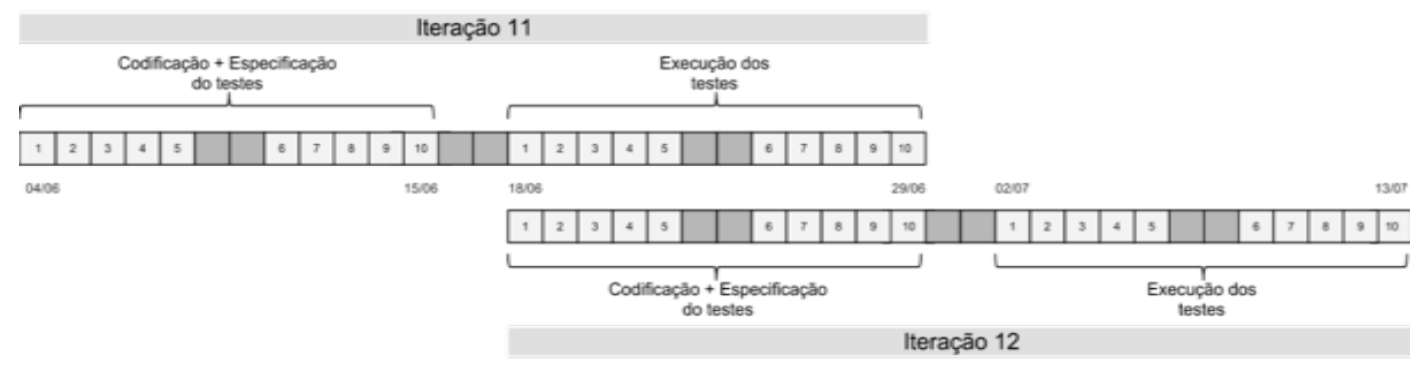

Figura 1. Iterações no processo da manutenção da Dataprev/PB

$\mathrm{Na}$ fase de planejamento, são realizadas as atividades de planejamento da iteração e contagem de pontos de função, caso a demanda seja uma melhoria. Se a contagem de pontos de função for superior a 200, a demanda é rejeitada. Caso contrário, os requisitos, regras, casos de uso e testes funcionais são especificados (fase de especificação).

Durante a fase de implementação, o código fonte é produzido e os testes unitários são realizados. Logo em seguida, a baseline é gerada e a aplicação atualizada é implantada em homologação. Em seguida, na fase de testes, após a preparação da execução, os testes funcionais manuais são realizados e a aplicação atualizada é disponibilizada para homologação com o cliente. Após homologação com o cliente, o produto é implantado em produção.

$\mathrm{Na}$ fase de encerramento, é realizada a contagem final de pontos de função, as lições aprendidas são registradas, a release é gerada e o termo de aceite do cliente é elaborado.

\section{Estudo de caso}

O estudo de caso foi realizado na Divisão de Manutenção de Produtos (DMP1) da Dataprev. A célula conta com 30 analistas de TI que desempenham atividades de codificação, especificação e gerência.

\subsection{Metodologia}

Com o objetivo de sondar a satisfação subjetiva dos membros da célula de manutenção em relação à adoção do processo descrito na Seção anterior, realizou-se um levantamento a partir da técnica de aplicação de questionário.

$\mathrm{O}$ instrumento de coleta de dados foi escolhido por ser de rápida aplicação, além de atingir um grande número de pessoas. Neste âmbito, Parasuraman (1991) afirma que construir questionários não é uma tarefa fácil e que aplicar tempo e esforço adequados para a construção do questionário é uma necessidade, um fator de diferenciação favorável. Neste sentido, o questionário aplicado foi bastante estudado antes de sua aplicação, sendo composto de sete questões objetivas e duas questões abertas. Nas questões objetivas foi utilizada a escala de Likert (1932) que consiste em uma escala de 
concordância usada habitualmente em questionários e uma das escalas mais usadas em pesquisas de opinião.

\subsection{Apresentação dos Resultados}

A equipe de manutenção da DMP1 possui 30 integrantes, onde 21 responderam ao questionário proposto. Dentre os respondentes, 16 são codificadores, 4 são especificadores e um é líder técnico. Do total de respondentes, $42,86 \%$ participava da equipe antes da implantação do processo descrito na Seção 3.

Nas questões relacionadas à sondagem da satisfação dos respondentes em relação ao processo, para uma melhor análise dos resultados, foi realizada uma abordagem quantitativa para estabelecer o ranking médio (RM) para o questionário que utilizou escala tipo Likert de 5 pontos (Likert, 1932) para mensurar o grau de concordância respondentes às assertivas apresentadas a eles.

Foi realizada verificação das respostas às questões avaliadas a partir da obtenção do ranking médio $(\mathrm{RM})$ da pontuação atribuída às respostas, relacionando à freqüência das respostas dos respondentes, onde os valores menores que 3 são considerados como discordantes e maiores que 3 , como concordantes, considerando uma escala de 5 pontos. O valor intermediário seria considerado "indiferente" ou "sem opinião", sendo o "ponto neutro" equivalente aos casos em que os respondentes deixaram em branco, como explicitado na Figura 2.

$\underline{\text { Discordo Totalmente }}$

Figura 2. Escala de Likert utilizada na sondagem da satisfação dos analistas de manutenção em relação ao processo utilizado

Para o cálculo do ranking médio foi utilizado o método de análise de escala do tipo Likert(1932) apresentado por Malhotra (2001). O resultado obtido pode ser verificado na Figura 3. A partir das respostas coletadas pode-se verificar que existe uma prevalência em relação à concordância em relação à adoção do processo utilizado pela divisão de manutenção da Dataprev/PB. O ranking médio (RM) calculado para cada questão pode ser visualizado no anexo A.

Na questão 6 buscamos analisar se os analistas acreditam que a implantação das práticas ágeis melhoraram o trabalho da manutenção. Esta análise utilizou uma questão subjetiva, onde $77 \%$ dos analistas que entraram na equipe após implantação do processo alegaram não ter parâmetro de comparação, visto que não faziam parte da equipe anteriormente. Em seguida, 22\% deles afirmaram que o trabalho da equipe melhorou, pois acreditam que a metodologia ágil aumenta a produtividade da equipe. 


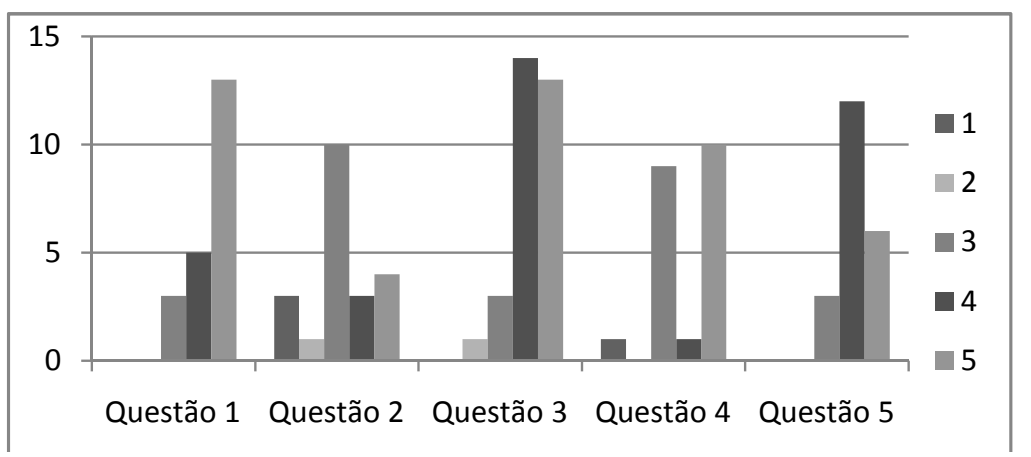

Figura 3. Resultado da sondagem da satisfação dos analistas de manutenção em relação ao processo utilizado

Os demais analistas, que já faziam parte da equipe antes da implantação da praticas ágeis, citam alguns ganhos com a adoção de práticas ágeis na célula de manutenção, entre eles:

- Maior organização e aumento da produtividade;

- Melhoria do planejamento;

- Rápido feedback através de iterações curtas de 15 dias e reuniões diárias com a equipe;

- Sincronia das iterações com os projetos;

- Flexibilização da equipe para disseminação do conhecimento; seguintes:

Do ponto de vista dos codificadores os fatores mais significativos foram os

- A comunicação entre os membros de equipe, com a adoção das stand-up meetings;

- Programação em pares para atender casos complexos.

Por fim, o questionário buscou levantar a percepção de equipe sobre necessidades de melhorias acerca das práticas utilizadas. Dos analistas que responderam o questionário, $61 \%$ afirmam que as práticas atuais estão totalmente adequadas às necessidades da área de manutenção.

Os demais analistas apresentaram alguns pontos que deveriam ser melhorados, listados a seguir:

- Maior participação dos Analistas de Negócio na especificação, sugerindo reuniões mensais para elucidação de dúvidas que impedem a resolução de um determinado problema;

- Treinamentos e acompanhamento mais próximo para os novatos da equipe de manutenção, especialmente relativos ao processo de desenvolvimento e demais normas da empresa;

- Melhor contagem dos pontos de função;

- Melhor priorização das atividades; 
- Criação de um ambiente de testes com massa de dados;

- Realização de brainstorms semanais ou quinzenais para melhorar a comunicação no desenvolvimento;

- Implantação de fórum de discussão interno para sugestões de melhorias e demandas;

- Divulgação de melhores práticas dentro das equipes, controle de métodos e classes depreciados;

- Um maior controle das versões lançadas, devido à grande dependência com as entregas dos projetos e entre os próprios sistemas.

\section{Considerações Finais e trabalhos futuros}

Considerando os resultados obtidos com o levantamento realizado, há indícios de que a abordagem ágil adotada pela célula de manutenção tem sido aceita pelos funcionários integrantes da célula. Uma das lições aprendidas foi que as práticas atuais ainda carecem de alguns ajustes, mas estão no caminho certo face às praticas que eram usadas anteriormente. Acredita-se que um fator motivador para a aceitação dessas práticas ágeis foi um ganho de produtividade da equipe com uma melhor organização do trabalho.

Como forma de disseminação das boas práticas adotadas, recomenda-se que o processo de manutenção seja formalizado e institucionalizado na empresa, visto que existem áreas de manutenção distribuídas na Dataprev em vários outros estados. Assim, será possível ter uma padronização da forma de trabalho das diferentes células de manutenção da Dataprev.

Como trabalho futuro, pretende-se realizar a avaliação das atividades no contexto de um processo formalizado, utilizando também outros métodos de coleta de dados, como entrevistas, para identificar melhorias no processo de manutenção e os ganhos reais obtidos pelas áreas de manutenção.

\section{Referências}

Erdil, Kagan; Finn, Emily; Keating, Kevin; Meattle, Jay; Park, Sunyoung; Yoon, Deborah. (2003) Software Maintenance As Part of the Software Life Cycle. Department of Computer Science Tufts University.

International Standards Organization. 2001. ISO 9126-1. Engenharia de software Qualidade de produto - Parte 1: Modelo de qualidade. 2001.

Likert ,Rensis (1932), "A Technique for the Measurement of Attitudes", Archives of Psychology 140: pp. 1-55

Malhotra, Naresh. Pesquisa de Marketing: uma orientação aplicada. Porto Alegre: Bookman, 2001.

Paduelli, M.M. (2007). Manutenção de Software: problemas típicos e diretrizes para uma disciplina específica. Dissertação de Mestrado. ICMC/USP.

Parasuraman, A. (1991) Marketing research. New York: Addison-Wesley. 
Pressman, R. S. (2001) “Software Engineering: A Practitioner's Approach”, McGraw Hill.

Sommerville, I. (2007) Engenharia de Software. 8th ed., Addison-Wesley.

\section{Anexo A}

\begin{tabular}{|c|c|c|c|c|c|c|}
\hline QUESTÃO 1 & \multicolumn{6}{|c|}{ FREQUÊNCIA DE SUJEITOS } \\
\hline \multirow{2}{*}{$\begin{array}{l}\text { Considero muito importante a } \\
\text { adoção de práticas como as } \\
\text { existentes atualmente para a célula } \\
\text { de manutenção. }\end{array}$} & 1 & 2 & 3 & 4 & 5 & $\mathrm{RM}$ \\
\hline & & & 3 & 5 & 13 & 4,7 \\
\hline QUESTÃO 2 & \multicolumn{6}{|c|}{ FREQUÊNCIA DE SUJEITOS } \\
\hline \multirow[b]{2}{*}{$\begin{array}{l}\text { O meu esforço individual de } \\
\text { trabalho na manutenção dos } \\
\text { produtos era maior antes da adoção } \\
\text { das práticas ágeis utilizadas } \\
\text { atualmente, pois o trabalho era } \\
\text { menos organizado. }\end{array}$} & 1 & 2 & 3 & 4 & 5 & RM \\
\hline & 3 & 1 & 10 & 3 & 4 & 3,1 \\
\hline QUESTÃO 3 & \multicolumn{6}{|c|}{ FREQUÊNCIA DE SUJEITOS } \\
\hline \multirow{2}{*}{$\begin{array}{l}\text { As práticas adotadas pela } \\
\text { manutenção } \\
\begin{array}{l}\text { adequadas às } \\
\text { estão totalmente } \\
\text { empresa. }\end{array}\end{array}$} & 1 & 2 & 3 & 4 & 5 & $\mathrm{RM}$ \\
\hline & & 1 & 3 & 14 & 3 & $\mathbf{3 , 9}$ \\
\hline QUESTÃO 4 & \multicolumn{6}{|c|}{ FREQUÊNCIA DE SUJEITOS } \\
\hline \multirow{2}{*}{$\begin{array}{l}\text { Na minha percepção a produtividade } \\
\text { da equipe como um todo aumentou } \\
\text { após a adoção das práticas ágeis, em } \\
\text { comparaça ao período anterior à } \\
\text { adoção. }\end{array}$} & 1 & 2 & 3 & 4 & 5 & $\mathrm{RM}$ \\
\hline & 1 & & 9 & 1 & 10 & $\mathbf{3 , 9}$ \\
\hline QUESTÃO 5 & \multicolumn{6}{|c|}{ FREQUÊNCIA DE SUJEITOS } \\
\hline \multirow{2}{*}{$\begin{array}{l}\text { Como você se sente em relação à } \\
\text { utilização das práticas adotadas } \\
\text { dentro da célula de manutenção? }\end{array}$} & 1 & 2 & 3 & 4 & 5 & $\mathrm{RM}$ \\
\hline & & & 3 & 12 & 6 & 4,1 \\
\hline
\end{tabular}

